\title{
A implementação do ensino remoto na pandemia: qual o lugar da educação especial?
}

\author{
Amanda Costa Camizão $0^{1}$ \\ ORCID: 0000-0002-3380-7877 \\ Patricia Santos Conde ${ }^{1}$ \\ ORCID: 0000-0002-5388-2866 \\ Sonia Lopes Victor ${ }^{1}$ \\ ORCID: 0000-0002-9492-6933
}

\section{Resumo}

Este artigo tem como objetivo analisar o processo de implementação do ensino remoto com vistas à garantia do atendimento educacional especializado aos estudantes públicoalvo da educação especial em tempo de pandemia da covid-19. Organiza-se com base nas experiências de duas docentes de dois municípios do Estado do Espírito Santo (ES). É um estudo documental, pois utiliza os registros produzidos pelas Secretarias de Educação. Diante da implementação do ensino remoto, surgiram alguns questionamentos, como: Por que as aulas precisam voltar? Quais as condições concretas de trabalho oferecidas aos professores da educação especial para a realização do ensino remoto? Como os municípios se organizaram para garantir o direito à educação do público-alvo da educação especial? Será que essas condições estão sustentando um trabalho inclusivo no contexto de pandemia? A produção e análise dos dados mostraram as possibilidades e limitações da implementação da educação especial na perspectiva da educação inclusiva, conforme orienta a política nacional de educação especial vigente. 0 estudo concluiu que a proposta de educação especial dos municípios não corresponde diretamente à proposta inclusiva prevista nas orientações anteriores ao período de pandemia. Se a proposta era estabelecer vínculos, os objetivos foram alcançados, mas, se ela se estende ao comprometimento com a aprendizagem e o desenvolvimento desses sujeitos, está bem longe de ser atingida.

\section{Palavras-chave}

Educação especial - Pandemia - Ensino remoto - Inclusão escolar.

1- Universidade Federal do Espírito Santo, Vitória (ES) - Brasil.

Contatos: amanda.ufes@gmail.com; patyconde@yahoo.com.br; sonia.victor@hotmail.com 


\section{Implementation of remote schooling during the pandemic: what is the place of special education?}

\section{Abstract}

This article analyzes the process of implementing remote schooling, aiming to guarantee specialized educational services for students of the target audience of special education during the covid-19 pandemic. It was organized based on the experiences of two teachers, from two cities of the same region. It is a documentary study, as it uses Municipal Education Department records. With the implementation of remote schooling, some questions arose, such as: Why do classes need to return to normality? What are the concrete working conditions offered to special education teachers for remote schooling? How did cities organize themselves to guarantee the right to education of the target audience of special education? Are these conditions supporting inclusive work in the context of a pandemic? The production and data analysis showed the possibilities and limitations of implementing special education from the perspective of inclusive education, as directed by the current national policy. It was concluded that the cities' special education proposal does not directly correspond to the inclusive proposal of the guidelines prior to the pandemic. If the proposal was committed to the establishment educational bonds, they achieved their goals, but if it is committed to the learning and development of these subjects, the goals were not achieved.

\section{Keywords}

Special education - Pandemic - Remote schooling - School inclusion.

\section{Introdução}

Em março de 2020, no Brasil, fomos surpreendidos por uma nova realidade já presente em outros países, a qual afetava progressivamente o mundo em virtude da contaminação pelo Sars-CoV-2, o coronavírus causador da covid-19. Apesar de a humanidade ter vivenciado pandemias em diferentes momentos históricos, quando doenças se espalharam e causaram grandes estragos, a situação instalada causou-nos medo e trouxe-nos inúmeros desafios diante do desconhecido. Em pouco tempo, tivemos de assimilar a imposição de uma nova rotina que não nos deu muitas escolhas sobre os caminhos que deveríamos seguir. De alguma forma, a sociedade buscava chegar a uma organização que tivesse semelhança com a antiga normalidade, o que não tem sido uma tarefa fácil para aqueles que planejam, tampouco para os que a executam. Orso (2020, p. 44) ressalta: "De qualquer modo, tanto para o mais frágil dos homens, como para o mais poderoso império, o novo coronavírus se encarregou de revelar a tremenda fragilidade humana”. 
Para preservar a maior quantidade de vidas possiveis, as quarentenas foram instituídas em todos os cantos do mundo, o que nos afastou de nossas atividades diárias e impactou duramente a economia de todos os países.

As exigências do capital pressionaram a sociedade para que encontrasse, na condição de quarentena, formas de continuar desenvolvendo os trabalhos, para diminuir os impactos do mercado financeiro que viriam em decorrência dessa nova organização. Inicialmente, o governo federal brasileiro apresentava resistência ao amparo à população trabalhadora. A condição precária do mercado de trabalho de nossa sociedade já é anterior à pandemia, e, de acordo com Praun (2020), as raízes dessa condição estão assentadas em especificidades sócio-históricas.

0 contexto de pandemia tanto evidenciou as mazelas de nossa sociedade como também ampliou a desigualdade social, fruto do legado neoliberal que, desde sempre, vem romantizando a precarização do trabalho. As empresas adaptaram-se ao teletrabalho, já os estabelecimentos comerciais adequaram-se ao serviço de vendas on-line com serviços de delivery. E, no contexto educacional, a saída foi por meio da instituição do ensino remoto, primeiramente pela rede particular, seguida das redes públicas.

Nesse cenário, a implementação do ensino remoto configurou-se como uma possibilidade de garantir o direito à educação dos estudantes brasileiros. Porém, nesse contexto, é desvelada a sociedade desigual em que vivemos: uma parcela com condições adequadas (acesso à internet, aparatos tecnológicos, espaço físico) que possibilitam o acesso às aulas on-line; e outra expressiva, sem acesso a condições básicas de saúde, habitação e alimentação, quiçá a aparatos tecnológicos (ALVES et al., 2020).

0 ensino remoto foi a saída encontrada, no entanto, ele é absolutamente seletivo, o que indica que a sua organização diz respeito tanto à implementação das aulas on-line quanto à adaptação das condições sociais adequadas.

0 público-alvo da educação especial (PAEE) matriculado nas escolas das redes públicas enfrenta, nesse momento, um duplo desafio: o primeiro refere-se às condições históricas de garantir a inclusão, presentes no processo de escolarização, amplamente discutido ao longo dos anos; o segundo emerge da pandemia e dos desafios para assegurar a inclusão no ensino remoto, de forma que promova a aprendizagem e o desenvolvimento desses sujeitos. Cury et al. (2020) reconhecem que o aluno com deficiência está sendo impactado significativamente com o fechamento das escolas e da ausência de suporte para atender às suas demandas.

Diante dessa circunstância, surgem questionamentos, tais como: Por que precisamos retornar? Quais as condições concretas de trabalho oferecidas aos professores da educação especial para a realização do ensino remoto? Como os municípios se organizaram para garantir o direito à educação do PAEE? Será que essas condições estão sustentando um trabalho inclusivo no contexto de pandemia?

A fim de encontrarmos respostas para essas perguntas, definimos como objetivo deste estudo, que ora relatamos neste artigo: analisar o processo de implementação do ensino remoto com vistas à garantia do atendimento educacional especializado aos estudantes público-alvo da educação especial em tempo de pandemia. 
Movidas por essas questões, registramos o processo de implementação do ensino remoto para o PAEE nos municípios de Cariacica e Vila Velha, situados na região metropolitana da Grande Vitória (ES). Quanto ao aspecto metodológico, a referida pesquisa caracteriza-se como um estudo documental, pois utiliza os registros produzidos pelas Secretarias de Educação (correspondências internas e publicação no Diário Oficial), os quais foram coletados e organizados de março a setembro de 2020. São dados sem tratamento analítico anterior e foram sistematizados para atender ao objetivo desta pesquisa (GIL, 2008).

A proposta deste estudo é fruto das vivências de duas professoras ${ }^{2}$ pesquisadoras que atuam nos municípios de Cariacica e Vila Velha e acompanharam o processo de implementação do ensino remoto. Elas estavam submetidas às orientações dadas pelas respectivas Secretarias de Educação ${ }^{3}$ por meio de reuniões institucionais, formações, planejamentos e elaboração de atividades. 0 fato de estarem inseridas em um grupo de pesquisa oportunizou um olhar crítico em relação aos acontecimentos advindos do contexto de pandemia da covid-19.

As discussões basearam-se na perspectiva histórico-crítica, porque ela nos auxilia na retomada do discurso crítico, empenhando-se em desvelar "as relações entre a educação e os seus condicionantes sociais, evidenciando a determinação recíproca entre prática social e prática educativa” (SAVIANI, 2011, p. 16), que devem fundamentar a constituição da proposta inclusiva do ensino remoto.

\section{O professor de educação especial e as instabilidades da pandemia}

Nas primeiras semanas da pandemia, o governo do Espírito Santo instituiu uma quarentena restrita, com a finalidade de evitar o aumento de notificações de casos de contaminação pelo novo coronavírus e possível superlotação em hospitais de toda a rede de saúde do estado. A situação não só afetou o funcionamento das escolas, mas também restringiu a participação nas atividades não essenciais. Consequentemente, o comércio local foi afetado, o que acarretou prejuízos no setor econômico em todos os âmbitos, incluindo a arrecadação dos municípios.

De acordo com a Aequus Consultoria, que publica a Revista Finanças dos Municípios Capixabas (2020), a retração da economia pode levar os 78 municípios capixabas a perder até 1 bilhão da receita própria. Comparado ao ano de 2019, há a possibilidade de recuo em até 15\%. 0 prefeito de Cariacica analisou o contexto e declarou em entrevista:

Os desafios que se impõem às cidades com as características de Cariacica sempre foram enormes e agora se mostram ainda maiores. Um município ainda jovem se comparado aos demais da Grande Vitória, completando 130 anos em dezembro de 2020, que apresenta grande porte

\footnotetext{
2- As duas professoras trabalham nas redes municipais de educação de Vila Velha e Cariacica e ocupam, respectivamente, os cargos de professora de educação especial e professora de educação infantil. Estão inseridas em um grupo de pesquisa e desenvolvem trabalhos sob a orientação da mesma professora.

3- Os municípios utilizam siglas diferenciadas para identificar a Secretaria de Educação dos municípios. Em Cariacica, é denominado SEME e, em Vila Velha, Semed. Durante a escrita do texto, utilizamos as siglas oficiais que cada município adota.
} 
populacional e desenvolvimento não planejado, com déficit de infraestrutura, o que acarreta uma série de efeitos, entre os quais a baixa arrecadação. Com o agravante do modelo de distribuição de recursos entre os entes federados, Cariacica figura historicamente como a menor receita per capita no Estado. (AEQUUS CONSULTORIA, 2020, p. 3).

Percebemos que o município de Cariacica já trabalha com limites muito restritos e a educação sentiu esse impacto no primeiro mês de pandemia, com cortes de estagiários e extensões de carga horária.

Em 2019, o município de Vila Velha obteve queda nas arrecadações municipais, entretanto não deixou de ser um ano promissor para a cidade que liderou a arrecadação entre as cidades capixabas, com o valor de $\mathrm{R} \$$ 88,2 milhões. Em relação à taxa de crescimento do Fundo Nacional de Manutenção e Desenvolvimento da Educação Básica (FUNDEB) de 2019, o município teve a segunda maior arrecadação (R\$148,6 milhões) do estado (AEQUUS CONSULTORIA, 2020).

No contexto da rede municipal de educação, apesar da pandemia e dos cortes que se fizeram imprescindíveis, o município tem conseguido cumprir com os contratos temporários dos professores de educação especial. Segundo os dados disponíveis no Portal Transparência de Vila Velha, o município tem 378 professores de educação especial (PE), dos quais 269 cumprem o regime de designação temporária e 109 são efetivos no cargo. Percebemos que mais de um terço desses profissionais atuam na condição de contratados, sem contar os professores que atuam realizando a extensão de carga horária, dado que não consta no Portal Transparência. A referida condição aponta a urgência de preenchimento do quadro efetivo de professores de educação especial no município.

Conforme vimos, trata-se de duas realidades bem distintas. 0 município de Vila Velha sentiu menos o impacto da pandemia, enquanto Cariacica, que já estava em condições difíceis, amarga o impacto da queda nas arrecadações. A seguir, apresentamos esses impactos na carreira dos professores de educação especial de ambos os municípios.

\section{Impactos das ações municipais sobre o professor de educação especial}

A pandemia afetou diretamente o professorado que atua na educação especial do município de Cariacica. Os professores designados para o trabalho na educação especial são, até 2020, os mesmos habilitados para o trabalho em regência de sala de aula regular. A seleção era feita por meio de prova interna oferecida pela Seme/coordenação responsável. Por esse motivo, todos os professores que atuam na educação especial no município não são ocupantes do cargo especificamente de educação especial. Além disso, muitos atuam nessa mesma área e no mesmo município há muitos anos. Outro fato que pesa é a possibilidade de fazer extensão de carga horária completa em outro turno, que é uma realidade muito comum na educação especial de Cariacica, conforme pode ser conferida no Portal Transparência.

Com relação ao cargo de professor de educação especial, devemos destacar que o município o criou em 2019, mais precisamente em 4 de janeiro de 2019, mediante a 
Lei Municipal $n^{\circ}$ 5.950. Se considerarmos a designação das atividades apresentadas nas Diretrizes Operacionais da educação especial para o AEE na educação básica (BRASIL, 2001), percebemos que o município não se preocupou em regularizar esse cargo. Trata-se, portanto, de uma forma de desvalorização do trabalho do professor de educação especial, pois o coloca em condições precárias e não institucionaliza o vínculo e as especificidades do cargo (GARCIA, 2017).

No município de Vila Velha, a seleção do cargo de professor de educação especial é realizada por meio de concurso público para profissionais efetivos, processo seletivo para a contratação de profissionais no regime de temporário e extensão de carga horária. Esse profissional tem uma área específica de atuação de acordo com a especificidade do estudante. Dessa maneira, encontramos os seguintes profissionais: Professor Educação Especial Bilíngue, Professor Educação Especial Deficiência Intelectual e Deficiência Múltiplas, Professor Educação Especial na Área de Deficiência Visual, Professor Educação Especial Tradutor e Intérprete - Língua Portuguesa, Professor Educação Especial Libras.

A Política Nacional de Educação Especial na Perspectiva da Educação Inclusiva PNEE-EI (BRASIL, 2008) reafırma o direito à educação inclusiva, além de definir o público de atendimento da educação especial, como aqueles com deficiências, transtornos globais do desenvolvimento/altas habilidades e superdotação (AH/SD). Entendemos que, ante essa definição do PAEE, os municipios poderiam basear-se para a criação do cargo de professor de educação especial; no entanto, eles não se adequam à demanda total.

No caso de Cariacica, o cargo é único e deve contemplar todas as especificidades dos estudantes PAEE. Essa é uma questão problemática referente à formação desses profissionais. A demanda é superior à exigência do cargo, que solicita formação em curso superior completo em licenciatura plena na área educacional e curso complementar específico na área em qualquer uma daquelas que definem o público, as quais totalizam carga horária mínima de 120 horas (CARIACICA, 2019).

Essa situação aproxima-nos das discussões de Vaz (2014), quando alerta a respeito da sobrecarga de funções atribuídas ao professor de educação especial, denominado pela autora de "professor multifuncional". Essa característica está longe de ser um "elogio", porque ressalta suas multitarefas e responsabilizações no processo de inclusão.

No caso de Vila Velha, percebemos uma organização diferenciada que distingue a área de atuação de cada profissional, o que auxilia nos seus planejamentos, formações e práticas. Contudo, a área de $\mathrm{AH} / \mathrm{SD}$ não está contemplada, ficando desassistida e à mercê de profissionais sem formação específica.

\section{A condição do professor em extensão de carga horária}

A extensão de carga horária é um vínculo que o professor estabelece com o município, quando há vacância temporária de uma vaga em um turno diferente de seu vínculo, seja efetivo, seja contratado. Quando o professor em extensão ocupa essa vaga, deve estar ciente de que esse vínculo existe até a chegada de um professor efetivo ou contratado, o que pode, ou não, acontecer no decorrer do ano.

Sendo assim, é um vínculo muito frágil, mas é disponibilizado em todos os anos e, em alguns casos, preenche cargos vagos pela falta de realização de concursos públicos 
para o preenchimento do quadro efetivo, como é o caso dos municípios em destaque. A extensão pode, ou não, preencher uma carga horária completa. Ressaltamos que, em Vila Velha, as extensões não foram cortadas durante a pandemia.

Já em Cariacica, as extensões foram cortadas desde 18 de março de 2020, de maneira que muitos professores tiveram suas rendas diminuídas pela metade. Em meados de julho, quando o município organizava o retorno das aulas na condição remota, foram disponibilizadas as extensões com a carga horária de 15 horas semanais para os professores da rede, exceto para aqueles que atuavam na educação especial. Essa situação foi apresentada em reunião com os gestores, ocorrida em 20 de julho de 2020, e posteriormente repassada aos professores das instituições de ensino.

A situação não atingiu unicamente os professores, mas também os alunos PAEE. Afınal, em muitas escolas, os profıssionais da educação especial atuavam na condição de extensão. Como ficaria o Atendimento Educacional Especializado (AEE) para os estudantes PAEE dessas instituições onde os professores estavam atuando em extensão? Essa decisão fere o direito do estudante, pois educação especial não é um serviço opcional, é um direito que deve ser ofertado (BRASIL, 2008).

A justificativa do corte dada pelo município foi a queda nas arrecadações, entretanto, o corte deve ser pensado de outra forma que não seja a retirada de direitos garantidos, como afirmam Dias e Pinto (2020, p. 1): “[...] por mais que a economia dos países sofra com a pandemia, os investimentos em Educação devem ser mantidos, quiçá aumentados”. Afınal, os cortes devem visar a gastos, e não a investimentos, como é o caso da educação, principalmente nesse momento em que a educação necessita de recursos para o auxílio nas adaptações que surgiram em razão da pandemia.

No entanto, passada uma semana, o município voltou atrás e publicou nova orientação, permitindo a possibilidade de extensão aos professores da educação especial em Cariacica, também com carga horária de 15 horas semanais (60 horas mensais).

Em nova orientação, publicada em 4 de setembro de 2020, por meio da CI n ${ }^{\circ}$ 259/2020, foi aberta a possibilidade de ampliação de carga horária para professores regentes, coordenadores e pedagogos de até 90 horas mensais. Os profissionais da educação especial foram excluídos novamente. 0 posicionamento, ou a falta deste, por parte da Seme, representa a perspectiva e a consideração dela em relação à educação especial do município.

A educação especial na PNEE-EI (2008) é tratada como um serviço. Constar como um serviço, no entanto, não reduz a sua importância nem flexibiliza a responsabilidade da oferta. A pandemia não pode servir como um suporte para esse tipo de compreensão. 0 fato de não estar em regência de sala de aula também não elimina o aspecto pedagógico do trabalho do professor da educação especial (GARCIA, 2017). Somente o acesso do aluno à escola não corresponde à promoção da inclusão, porque esta deve estar articulada ao AEE; por isso, a necessidade do professor especializado.

Outro ponto de destaque é a instabilidade do professor na condição de extensão. Além de não ter direitos trabalhistas no horário que estende, há a instabilidade do vínculo, pois está à mercê das ações do município. Essa é uma condição de desvalorização do trabalho docente, por esse motivo é necessária a promoção de concurso público que dê estabilidade, acesso a direitos trabalhistas e continuidade do trabalho pedagógico com os alunos PAEE. 


\section{O concurso público e os entraves municipais}

Conforme vimos na discussão anterior, ambos os municípios necessitam de preenchimento do quadro efetivo dos professores de educação especial. No caso de Cariacica, a justificativa ocorre pela necessidade de preencher todas as vagas, pois o cargo é recente e os profissionais que ocupam não são designados para tal, a não ser os que estão vinculados por meio de contratos temporários. Em Vila Velha, a vacância para o cargo de educação especial é tão grande a ponto de ter dois terços a mais de professores contratados em relação aos efetivos.

Em dezembro de 2019, o município de Vila Velha abriu concurso público para o provimento de cargos efetivos do quadro do magistério de diferentes áreas do conhecimento. Para o cargo de professor de educação especial, foram abertas 183 vagas distribuídas entre Professor Educação Especial Bilíngue, Professor Educação Especial Deficiência Intelectual e Deficiência Múltiplas, Professor Educação Especial na Área de Deficiência Visual, Professor Educação Especial Tradutor e Intérprete - Língua Portuguesa, Professor Educação Especial Libras (VILA VELHA, 2019).

No entanto, a pandemia afetou o andamento do concurso. Alguns cargos exigiam prova prática, a saber: professores da Educação Especial Libras, Educação Especial na área de Deficiência Visual, Educação Especial Bilíngue e Educação Especial Tradutor e Intérprete - Língua Portuguesa - Libras. Apesar disso, o concurso foi parcialmente homologado no início de agosto e considerou apenas a área da deficiência intelectual, pois essa não continha prova prática. Após a finalização das provas práticas, as demais áreas poderão ser homologadas.

A criação do cargo em Cariacica, no início de 2019, tornou necessária a abertura de concurso para a seleção de professores efetivos. 0 edital foi aberto no fim do ano passado e as provas foram realizadas em janeiro de 2020. A divulgação de resultados foi paralisada, tendo como justificativa a pandemia.

0 concurso foi aberto para o preenchimento de apenas 50 vagas, lembrando que não há efetivo nesse cargo e o preenchimento deve contemplar todas as instituições que atendem estudantes público-alvo da educação especial. Se consideramos que o município tem mais de cem instituições de ensino, entre Centros Municipais de Educação Infantil e Escolas Municipais de Ensino Fundamental, as vagas não correspondem a essa demanda. Percebemos que o município está longe de alcançar a demanda da área. Assim, ou terão de chamar além do número de vagas previstas no edital do concurso, ou a maioria dos professores serão contratados, o que não parece ter respaldo legal. Além dessa possibilidade, só resta a opção de que eles continuem em desvio de função.

A pandemia impactou diretamente o andamento dos concursos para professores de educação especial dos municípios pesquisados. Com base na Lei Complementar $n^{\circ} 173$, de 27 de maio de 2020, que estabeleceu o Programa Federativo de Enfrentamento ao Coronavírus Sars-CoV-2, ficou proibida a realização de concurso público, exceto para as reposições de vacâncias, além da proibição de admissão de pessoal que acarrete aumento da despesa. Apegados a essas determinações, os municípios tiraram de pauta a finalização dos concursos. 
Porém, o Parecer SEI no 13053/2020/ME, publicado no fim de agosto, esclareceu a Lei $n^{\circ} 173$, de 27 de maio de 2020, sobre o preenchimento das vacâncias, ao afirmar que o documento "[...] não delimitou, de modo expresso, o momento no qual essas vacâncias devem ocorrer para que possam ser preenchidas durante o período restritivo" (BRASIL, 2020). Por esse motivo, as vacâncias a serem preenchidas não estão restritas ao surgimento pós-pandemia. Sendo assim, não há impedimento para a conclusão de chamada de efetivos, pois é pública a vacância dos cargos de educação especial nos municípios de Cariacica e Vila Velha.

No caso de Cariacica, só restava ao município a publicação dos resultados finais e homologação. Em Vila Velha, ainda havia a necessidade de aplicação das provas presenciais. Depois da pressão popular realizada pelos candidatos e de denúncias ao Ministério Público, o município de Vila Velha, como já dissemos, homologou os cargos finalizados (DAL GOBBO, 2020).

Como vimos argumentando, a pandemia trouxe uma série de prejuízos à população e não deixou de fora os profissionais da educação especial. Além da problemática referente à saúde mundial, estão enfrentando os desafios burocráticos impostos pelos governantes que demonstram uma falta de interesse na valorização dos serviços públicos.

\section{A implementação do trabalho remoto nos municípios e o lugar da inclusão}

Neste tópico, tivemos como intenção a realização de um diálogo acerca do processo de implementação do trabalho remoto da educação especial, considerando a proposta organizada pelas Secretarias de Educação dos municípios. Apresentamos primeiramente a proposta de Vila Velha e posteriormente a de Cariacica.

\section{A proposta de Vila Velha}

Em 17 de março de 2020, o município de Vila Velha suspendeu as atividades do magistério e aulas nas instituições da Rede Pública Municipal até o dia 4 de abril de 2020, assegurando que não haveria prejuízo da manutenção do calendário escolar4.

Após a análise do decreto, entendemos que a suspensão se refere às atividades presenciais dos estudantes e dos profissionais da educação, porém a orientação da Semed foi que os professores teriam de cumprir com a carga horária semanal com a presença física. Somente no dia seguinte (18 de março), foi informado que os profissionais estariam liberados até o dia 6 de abril. A partir desse período, a suspensão das aulas foi prorrogada ao fim de cada mês mediante os decretos municipais. A última suspensão está prevista até o dia 30 de setembro de $2020^{5}$.

$\mathrm{Na}$ primeira quinzena ainda de abril, a Semed solicitou a colaboração dos professores de todas as áreas do conhecimento para o envio de atividades que comporiam

4- A suspensão foi regulamentada pelo Decreto nº 042/2020, no qual o município declarou Situação de Emergência de Saúde Pública, decorrente da pandemia do novo coronavírus.

5- Ressaltamos que encerramos a catalogação dos dados no início de setembro de 2020. 
a plataforma on-line de aprendizado à distância. Segundo a orientação da Semed, as atividades da educação especial deveriam estar de acordo com a proposta curricular da etapa correspondente à matrícula do estudante.

Nesse momento, não era clara a orientação sobre a organização da plataforma, nem houve nenhuma instrução específica para a organização do trabalho dos professores de educação especial. A alternativa foi planejar (de forma virtual) como solicitado aos professores regentes. Ressaltamos que não houve nenhuma orientação sobre esse tipo de planejamento, se seriam adaptações ou se seriam atividades diferenciadas direcionadas a esse público específico.

Em 13 de abril, o município iniciou as atividades não presenciais por meio da plataforma on-line Conectados da Vila, com a publicação de atividades semanais para serem desenvolvidas de forma virtual. Essas atividades são disponibilizadas no site e distribuídas na escola semanalmente para aqueles que têm dificuldades em acessar a internet. As referidas atividades entraram na contagem de horas-aula não presenciais. Sendo assim, esse período sem atividades presenciais não será reposto, uma vez que todos os professores estiveram trabalhando em atividade remota.

\section{A proposta de Cariacica}

No município de Cariacica, as atividades presenciais foram suspensas mediante o Decreto $n^{\circ}$ 055, publicado no Diário Oficial, em 17 de março de 2020. 0 art. $1^{\circ}$ do documento previu a suspensão das aulas inicialmente pelo período de 15 dias, podendo ser ampliado, o que foi acontecendo ao final dos prazos estabelecidos por meio de decretos publicados no Diário Oficial (março, abril, maio, junho, julho e agosto).

Desde 18 de março até 2 de agosto de 2020, não houve aula remota organizada pelas instituições de ensino. Nesse período, o município organizou uma página online (\#Dever em Casa) para a publicação de materiais e atividades semanais a serem desenvolvidas durante o período da quarentena. 0 site deixava claro que as atividades não possuíam caráter obrigatório, nem seriam substitutivas às aulas presenciais. As atividades da plataforma iniciaram em abril/2020 e continuam ativas. A elaboração das atividades está sendo feita pelos técnicos da Seme em parceria com as instituições de ensino. Cabe destacar que a Seme orientou as instituições para que fizessem a impressão desses materiais para a entrega aos alunos que não tivessem acesso on-line.

No entanto, na Circular Interna/SEME-GAB-PMC - No 242/2020, enviada aos profissionais da educação em 31 de julho de 2020, consta que as horas relativas às interações com os alunos realizadas por meio do site \#Dever em Casa, bem como pelas atividades impressas, correspondentes ao período de 14 de abril a 27 de julho de 2020, deveriam ser contabilizadas como atividades remotas desse período (CARIACICA, 2020, p. 16).

0 site \#Dever em casa hospeda uma página específica para a educação especial, na qual não consta lista de atividades desenvolvidas pelos professores da educação especial, tampouco adaptadas. No que concerne à realização das atividades do site pelos estudantes PAEE, se aconteceu, foi sem nenhuma adaptação pedagógica, pois, até o fim de julho/2020, não havia direcionamento ao professor. 
Percebe-se que a página da educação especial do \#Dever em Casa é direcionada aos professores e contém materiais específicos (guias educacionais) focados em algumas deficiências: transtorno do espectro autista, paralisia cerebral, atrofia muscular espinhal e deficiência física. Há uma infinidade de vídeos com viés educativo e informativo, com exemplos de superação e outras temáticas. Em uma aba denominada "Experiências exitosas", há também os vídeos sobre experiências de profissionais com algumas crianças da rede. Os textos informativos tomam como referência a legislação específica da área.

Ao final de 2019, o município adquiriu a plataforma Google for Education, como consta na CI $n^{\circ}$ 242. No período de pandemia, o recurso se apresentou como uma possibilidade de interação entre os alunos e professores. Por esse motivo, foi sendo atualizada mediante o cadastro e criação de e-mails institucionais para professores, pedagogos e coordenadores. Pelo tempo e urgência que o contexto demandava, o período de cadastramento concretizou-se em meados de maio, quando foram iniciadas algumas formações para esses grupos.

Posteriormente, os alunos também foram sendo cadastrados, com o objetivo de criar as salas de aulas (Classroom) para que o professor organizasse as atividades pedagógicas. Por esse aplicativo, é possível criar turmas, distribuir tarefas, atribuir notas e enviar feedbacks aos alunos. Além desse aplicativo, a plataforma oferece opções de interação entre professores e alunos, entre professores e gestores das instituições. Assim, têm sido realizadas as reuniões dos gestores e pedagogos com os profissionais da escola. A plataforma é também uma ferramenta que possibilita a relação da Secretaria de Educação com o professor por meio das formações para alguns grupos, como o caso da educação especial.

Apesar de tantos recursos, a plataforma Google for Education está restrita ao uso dos professores e técnicos da Seme, e as aulas remotas ainda não foram implementadas, até porque o cadastro dos alunos ainda não foi concluído até o momento (setembro/2020).

Ante as orientações da CI no 242, os professores começaram a produzir, em agosto, sequências de atividades para a entrega aos alunos de suas turmas especificamente, definindo quantidade e formatação. A organização dessa entrega está a cargo da escola. Somente a partir desse momento, os professores de educação especial tiveram condições de iniciar as adaptações dessas atividades às especificidades dos alunos PAEE.

\section{O processo de implementação do ensino remoto: qual o lugar da educação especial?}

A educação especial insere-se no ensino regular como garantia de plena participação, aprendizagem e desenvolvimento do estudante PAAE. Essa implementação da educação especial nas instituições de ensino na condição presencial não se configura como um processo simples e linear. 0 acumulado de pesquisas da área sustenta essa constatação (JANNUZZI, 2012; KASSAR, 2011). 0 grande desafio nessa circunstância é a implementação desse serviço no momento de pandemia, considerando que as atribuições não foram pensadas para a realidade atual. Ações fundamentais para a efetivação do AEE estão momentaneamente suspensas. Diante disso, é nítida a impossibilidade de mera reprodução das ações presenciais no contexto on-line. 
0 repensar as práticas para o teletrabalho do professor demanda necessariamente o tempo para entender a realidade. Identificamos que as ações tomadas para a implementação do trabalho remoto nos municípios de Vila Velha e Cariacica ocorreram distintamente, a começar pela disparidade em relação ao tempo de implementação das ações. Vila Velha iniciou o trabalho no site Conectados da Vila, assegurando essa ação como uma atribuição do trabalho docente. Para isso, solicitou a produção de atividades semanais, que poderiam ser postadas na plataforma on-line, inclusive para os professores de educação especial. Esse foi o primeiro passo tomado em abril e perpetua sem grandes alterações até setembro.

A educação especial foi considerada para o referido município como um segmento da educação básica com demanda de atividades específicas. Essa concepção afasta-se totalmente da proposta do AEE. Cury et al. (2020) reconhecem que o AEE não está limitado ao espaço físico da sala de recursos multifuncionais, portanto:

[...] em tempos de pandemia, pode e deve ser oferecido aos estudantes que dele necessitem, possibilitando atividades pedagógicas remotas ricas em oportunidade para que cada um aprenda de acordo com suas possibilidades. (CURY et al., 2020, p. 4).

A respeito do trabalho docente do professorado da educação especial, não houve nenhuma orientação para a sua efetivação. Consequentemente, também não houve nenhuma orientação sobre a efetivação do AEE, ao que parece, e a urgência em apresentar à sociedade uma resposta sobre a organização da educação nesse novo contexto reduziu as condições de análise dos aspectos educacionais que vão muito além do planejamento e envio de atividades semanalmente.

Faltou ao município o reconhecimento das reais atribuições do trabalho docente do professor de educação especial. Como essas atribuições foram suprimidas, o momento de pandemia possibilitou a criação de uma nova/velha especificidade que mais se assemelha ao trabalho nas classes especiais, regredindo quase 20 anos ao período de integração em que os alunos estavam na escola, mas separados das turmas regulares (PADILHA, 2015).

Os municípios suspenderam as atividades presenciais na mesma semana, no entanto, as propostas de ensino remoto foram organizadas em momentos muito distintos. Se Vila Velha se organizou em duas semanas, Cariacica precisou de muito mais tempo para compreender a realidade e propor ações. Sabemos que as condições econômicas são muito diferentes nessas cidades. Por isso, o município teve de considerar as condições financeiras próprias e de sua população.

Cariacica também iniciou em abril a proposta de uma plataforma on-line para a postagem de atividades, porém ainda consta no site a informação de que essas atividades não serão contabilizadas como carga horária de ensino. Ou seja, por mais que houvesse uma proposta, ela não poderia ser considerada como ensino remoto.

A proposta inicial era a utilização dos aplicativos do Google for Education adquirido no ano anterior, mas o cadastramento dos profissionais foi moroso a ponto de estar finalizado apenas em maio. Além disso, não havia iniciado o cadastramento dos alunos, ou seja, quaisquer propostas que adviessem da utilização desses aplicativos estariam impossibilitadas pela limitação do acesso, pela falta de cadastro dos alunos e pela dificuldade de acesso de parte da população. A iniciativa de compra desse material 
foi importante apenas para o desenvolvimento dos planejamentos, reuniões de equipe e formações para os profissionais da educação.

Como em Vila Velha, a plataforma \#Dever em Casa de Cariacica também conta com uma página específica da educação especial, mas a intencionalidade dela é totalmente diferente. Em Cariacica, a página aparenta ser um suporte técnico e metodológico ao professor de educação especial e não contém nenhuma atividade específica voltada para o PAEE. Essa proposta aproxima-se do que Cury et al. (2020, p. 04) entendem como o trabalho do professor de educação especial na pandemia:

[...] o apoio que deve ser dado aos professores da sala de aula comum na escolha das atividades curriculares que serão enviadas. Assim, as barreiras atitudinais, tecnológicas e comunicacionais, que se fazem tão presentes na realidade da maioria dos estudantes com deficiência, transtorno do espectro autistas e altas habilidades, serão minimizadas ou até mesmo eliminadas.

Apesar de as informações estarem disponíveis no site, ainda não havia nenhuma orientação sobre o trabalho com o estudante, incluindo o da educação especial. 0 professor só estabeleceu contato com seus alunos no início de agosto. Até então, não havia atividade produzida pela instituição, tampouco possibilidades de adaptação às necessidades do PAEE. Outro destaque é a compreensão de educação especial do município, tendo em vista que muitos textos estão voltados para as questões biológicas referentes às especificidades dos alunos, o que desprivilegia conhecimentos específicos de cunho teórico e metodológicos da área.

Ao analisarmos ambas as propostas, percebemos que elas se aproximam na intencionalidade de desenvolver um apoio pedagógico aos estudantes PAEE dos municípios no período de pandemia pelas plataformas on-line. Assim como desenvolveram as referidas plataformas, também buscaram alternativas para os alunos que não têm acesso aos recursos tecnológicos.

Contudo, as propostas são completamente diferenciadas. Ao professor de educação especial do município de Vila Velha ficou a responsabilidade da produção das atividades que são atributos do professor regente das turmas em que se inserem os estudantes PAEE. Já em Cariacica, é claro o caráter de suporte esperado do professor de educação especial.

A diferença das propostas não ficou restrita à questão temporal, mas principalmente ao produto desenvolvido. 0 ensino remoto em si já é seletivo. Elaborar uma proposta de educação especial mediante essa condição é um grande desafıo. Todavia, é inaceitável que se organize, desconsiderando a intencionalidade de educação especial na perspectiva inclusiva adotada em nosso país.

As propostas despertam-nos para a seguinte questão: Qual foi a intencionalidade do trabalho remoto instituído nas redes municipais de ensino analisadas? Percebemos que a proposta de Vila Velha está mais próxima da necessidade de estabelecer vínculos pedagógicos com os alunos do que com a da garantia da aprendizagem deles. Já a proposta de Cariacica está mais bem elaborada, mas deixou os alunos sem suporte específico pelo período de quatro meses.

A preocupação do direito à educação não se limita à oferta de atividades, mas principalmente ao que a educação representa para o estudante. Dentro da perspectiva 
histórico-crítica, a finalidade da escola é a transmissão sistematizada dos conhecimentos produzidos pela humanidade ao longo da história (SAVIANI, 2011).

Diante de um ano atípico, seria realmente necessário o cumprimento das 800 horas letivas? De acordo com Cury et al. (2020), devemos lembrar que o primeiro direito a ser garantido é o direito à saúde, pois ela possibilita a garantia à vida e aos demais, incluindo o direito à educação.

\section{Considerações finais}

A pergunta central que desponta dos acontecimentos apresentados no texto é esta: "Por que as aulas precisam voltar?" A forma pela qual ela se estabelece é a própria resposta, que tem como base a urgência econômica em retomar a sensação de normalidade. Orso (2020) faz uma análise das relações atuais e propõe:

Imagine como seria se vivêssemos em uma sociedade em que o interesse coletivo prevalecesse e a defesa da vida fosse uma preocupação de todos. Certamente não estaríamos discutindo se a economia ou a vida é mais importante. (ORSO, 2020, p. 46).

No caso dos municípios pesquisados, a percepção que tivemos em Vila Velha é a necessidade de mostrar algum tipo de ação, que, no formato atual, se constitui como algo mecanizado de mera realização de atividades. No caso de Cariacica, percebemos a dificuldade em definir estratégias sistematizadas. Não podemos esquecer que as condições econômicas são muito diferentes e foram determinantes para a forma de implementação das atividades remotas. Em Cariacica, a primeira ação foi o corte da carga horária extensiva, que culminou no corte de muitos professores de educação especial. Esse tipo de vínculo permite aos municípios um controle do que eles entendem como gasto; entretanto, põe os professores em situação desfavorável e retira os direitos dos alunos.

As administrações públicas municipais, pautadas nas determinações federais, aproveitaram-se da pandemia para prolongar temporariamente o processo de admissão dos professores de educação especial efetivos. Esse contexto aponta que, nos momentos de crise, o capital atua na retirada dos direitos dos trabalhadores em nome de um bem maior. Percebe-se que as atribuições dos professores aumentam na mesma proporção em que os direitos diminuem.

A implementação da educação especial já é instituída na intenção do rompimento das barreiras sociais presentes na configuração da sociedade. A ação pedagógica do professor de educação especial requer o acompanhamento diferenciado, que atenda às necessidades dos estudantes PAEE. A identificação dessas necessidades à distância tornase uma tarefa quase impossível. 0 desafio aumenta sua implementação no contexto de pandemia, porque o trabalho desse professor compreende essas especificidades.

Nesse momento, o professor de educação especial precisa estabelecer outros tipos de vínculos pedagógicos com os estudantes PAEE. De forma geral, a educação precisa estar sensível às condições dos alunos e entender que os estudantes que aparecem nas telas digitais não são os mesmos que estavam sentados nas carteiras das escolas. 
Nos municípios, o trabalho remoto efetivou-se burocraticamente, mas está muito distante de contemplar os objetivos propostos. Ao que pudemos perceber, com base nas discussões realizadas, é que a educação especial tem sido considerada uma condição secundária na implementação desse ensino remoto, no momento de pandemia.

A educação é um direito inalienável e incondicional de todos sem restrições (BRASIL, 1988), o que leva à constatação de que esse direito vai muito além da questão do acesso. A proposta de educação especial dos municípios não corresponde diretamente à proposta inclusiva prevista nas orientações anteriores ao período de pandemia. Se a proposta era estabelecer vínculos, eles alcançaram os seus objetivos, mas, se ela se estende ao comprometimento com a aprendizagem e o desenvolvimento desses sujeitos, está bem longe de ser atingida.

\section{Referências}

AEQUUS CONSULTORIA. Revista das Finanças dos Municípios Capixaba, Vitória, Ano 26, 2020.

ALVES, Thiago et al. Implicações da pandemia da COVID 19, para o financiamento da educação básica. Revista de Administração Pública, Rio de Janeiro, v. 54, n. 4, p. 979-993, 2020. Disponível em: https:// bibliotecadigital.fgv.br/ojs/index.php/rap/article/view/81896. Acesso em: 6 out. 2021.

BRASIL. Constituição [da] República Federativa do Brasil. Brasília, DF: Senado Federal, 1988. Disponível em: http://www.planalto.gov.br/ccivil_03/constituicao/constituicao.htm. Acesso em: 23 ago. 2020.

BRASIL. Lei Complementar $n^{0}$ 173, de 27 de maio de 2020. Estabelece o Programa Federativo de Enfrentamento ao Coronavírus SARS-CoV-2 (Covid-19), altera a Lei Complementar $n^{0} 101$, de 4 de maio de 2000, e dá outras providências. Disponível em: http://www.planalto.gov.br/ccivil_03/leis/lcp/lcp173. htm. Acesso em: 11 set. 2020.

BRASIL. Conselho Nacional de Educação. Câmara de Educação Básica. Resolução CNE/CEB nº 2, de 11 de setembro de 2001. Institui diretrizes nacionais para a educação especial na educação básica. Brasília, DF: MEC/SEESP, 2001. Disponível em: http://portal.mec.gov.br/seesp/arquivos/pdf/diretrizes.pdf. Acesso em: 23 abr. 2018.

BRASIL. Ministério da Economia. Parecer SEI No 13053/2020/ME. Brasília, DF: ME, 2020. Disponível: https://dhg1h5j42swfq.cloudfront.net/2020/08/31083359/SEI_ME-9800026-Parecer-1.pdf. Acesso em: 11 set. 2020.

BRASIL. Ministério da Educação. Política nacional da educação especial na perspectiva da educação inclusiva. 2008. Brasília, DF: MECISESP, 2008. Disponível em: http://peei.mec.gov.br/arquivos/politica_ nacional_educacao_especial.pdf. Acesso em: 14 set. 2012; 23 abr. 2018.

CARIACICA. S. Lei Municipal $n^{\circ} 5.950$ de 04 de janeiro de 2019. Cria o Cargo de Educação Especial [...]. Diário oficial do Município de Cariacica. Cariacica (ES), 2019. Disponível em: https://www.cariacica. 
es.gov.br/wp-content/uploads//2019/01/DIARI0-OFICIAL-MUNICIPAL-07-01-2019-MLCOELHOassinado. pdf. Acesso em: 11 set. 2020.

CARIACICA. Circular Interna /SEME-GAB-PMC, Cariacica, n. 242, 31 jul. 2020.

CARIACICA. Circular Interna /SEME-GAB-PMC, Cariacica, n. 259, 4 set. 2020.

CARIACICA. Decreto n. 055, de 16 de março de 2020. Diário Oficial Municipal, Cariacica, n. 1282, 17 mar. 2020. Disponível em: https://www.cariacica.es.gov.br/static/files/diario/DI\%C3\%81RI0\%200FICIAL\%20 17-03-2020\%20-\%20EDI\%C3\%87\%C3\%830\%20N\%C2\%B0\%201282\%20\%20-\%202(assinado).pdf. Acesso em: 11 set. 2020.

CURY, Carlos Roberto Jamil et al. 0 aluno com deficiência na pandemia. [S. I.]: Instituto Fabris Ferreira, 2020. Disponível em: https://www.issup.net/pt-br/knowledge-share/news/2020-07/aluno-comdeficiencia-pandemia. Acesso em: 10 set. 2020.

DALL GOBBO, Eliane. Aprovados em concurso denunciam gestão de Max Filho ao MPES. Século Diário, Vitória, 11 set. 2020. Disponível em: https://www.seculodiario.com.br/cidades/aprovados-em-concursodenunciam-gestao-de-max-filho-ao-ministerio-publico-de-vila-velha. Acesso em: 05 ago. 2020.

DIAS, Érika; PINTO; Fátima Cunha Ferreira. A educação e a Covid-19. Ensaio, Rio de Janeiro, v. 28, n. 108, Editorial, jul./set. 2020. Disponível em: https://doi.org/10.1590/S0104-40362019002801080001. Acesso em: 05 ago. 2020.

GARCIA, Rosalba Maria Cardoso. Disputas conservadoras na política de educação especial na perspectiva inclusiva. In: GARCIA, Rosalba Maria Cardoso (org.). Políticas de educação especial no Brasil no início do Séculos XXI. Florianópolis: UFSC/CED/NUP, 2017. p. 19-66. Disponível em: https://gepeto.paginas. ufsc.br/files/2018/03/Livro-Rosalba_2017.pdf. Acesso em: 10 set. 2020.

GIL, Antonio Carlos. Métodos e técnicas de pesquisa social. 6. ed. São Paulo: Atlas. 2008.

JANNUZZI, Gilberta Sampaio de Martino. A educação dos deficientes no Brasil: dos primórdios ao início do século XXI. 3. ed. Campinas: Autores Associados, 2012.

KASSAR, Mônica de Carvalho Magalhães. Educação especial na perspectiva da educação inclusiva: desafios da implantação de uma política nacional. Educar em Revista, Curitiba, n. 41, p. 61-79, jul./set. 2011. Disponível em: http://www.scielo.br/pdf/er/n41/05.pdf. Acesso em: 05 ago. 2020.

ORSO, Paulino José. 0 novo coronavírus, pedagogia histórico-crítica, a sociedade de classes e o internacionalismo proletário. Revista Exitus, Santarém, v. 10, n. 1, e020048, 2020. Disponível em: http://www.ufopa.edu.br/ portaldeperiodicos/index.php/revistaexitus/article/view/1432/849. Acesso em: 11 set. 2020.

PADILHA, Anna Maria Lunardi. Possibilidades de histórias ao contrário: ou como desencaminhar 0 aluno da classe especial. São Paulo: Plexus, 2015.

PRAUN, Luci. A espiral da destruição: legado neoliberal, pandemia e precarização do trabalho. Revista Trabalho, Educação e Sociedade, Rio de Janeiro, v. 18, n. 3, e00297129, 2020. Disponível em: https:// www.scielo.br/j/tes/a/xLpYsdjK4xWDWHkmkSVLFyf/abstract/?lang=pt. Acesso em: 06 out. 2020. 
SAVIANI, Demerval. Pedagogia histórico-crítica: primeiras aproximações. 10. ed. Campinas,: Autores Associados, 2011.

VAZ, Kamille. 0 professor de educação especial nas políticas de perspectiva inclusiva no Brasil: concepç̃̃es em disputa. In: REUNIÃO DA ANPED - ASSOCIAÇÃO NACIONAL DE PÓS-GRADUAÇÃO E PESQUISA EM EDUCAÇÃO SUL, 10., 2014, Florianópolis. Anais... Florianópolis: Anped, 2014. p. 1-19.

VILA VELHA. Edital de concurso público. Diário Oficial do Município de Vila Velha, Vila Velha, n. 001/2019, 13 dez. 2019.Disponível em: https://www.vilavelha.es.gov.br/midia/paginas/Diario_Oficial_VilaVelha_13-12-2019_835_1. pdf. Acesso em: 11 set. 2020.

VILA VELHA. Decreto N. 042/2020, de 19 de março de 2020. Diário Oficial do Município de Vila Velha, Vila Velha, 20 mar. 2020. Disponível em: https://www.vilavelha.es.gov.br/legislacao/Arquivo/Documents/ legislacao/html/D422020.html. Acesso em: 11 set. 2020.

Recebido em: 31.10.2020

Revisado em: 11.02.2021

Aprovado em: 06.04.2021

Amanda Costa Camizão é pedagoga pela Universidade Federal do Espírito Santo (UFES), especialista em educação especial, mestra e doutoranda em educação pela UFES. Atua como professora das redes municipais de educação de Cariacica e Vila Velha (ES).

Patricia Santos Conde é pedagoga pela Universidade Federal do Espírito Santo (UFES), mestra e doutoranda em educação pela UFES. Atua como professora das redes municipais de Vitória e Vila Velha (ES).

Sonia Lopes Victor é pós-doutora em educação especial pela Universidade Federal de São Carlos (PDS). É professora titular do Centro de Educação da Universidade Federal do Espírito Santo (UFES), vinculada ao Departamento de Teorias do Ensino e Práticas Educacionais. Credenciada ao Programa de Pós-Graduação em Educação da UFES. 